\title{
ANALISIS PENGARUH PEMBANGUNAN INFRASTRUKTUR PELAYANAN DASAR, JALAN PROVINSI, AIR BERSIH, HOTEL, PENGINAPAN DAN RESTORAN TERHADAP PRODUK DOMESTIK REGIONAL BRUTO
}

\author{
Andi Rokhmat ${ }^{1}$, Hadi Sasana ${ }^{2}$, Nugroho SBM $^{3}$, Edy Yusuf ${ }^{4}$ \\ andieandong@gmail.com
}

Magister Ilmu Ekonomi dan Studi Pembangunan, Universitas Diponegoro, Semarang, Indonesia

\section{Info Artikel}

\section{Sejarah Artikel:}

Diterima : 13 Juli 2020

Disetujui : 22 Agustus 2020

Dipublikasikan :25 Agustus 2020

Keywords:

PDR; infrastruktur

Pendidikan; infrastruktur

kesehatan; jalan raya

provinsi; infrastruktur air

bersih; hotel penginapan

dan restoran.

\begin{abstract}
Abstrak
Penelitian ini bertujuan menganalisis pengaruh produk domestik regional bruto (PDRB) yang dipengaruhi oleh pembangunan infrastruktur pelayanan dasar, jalan provinsi, air bersih, serta hotel, penginapan dan restoran pada 35 kabupaten dan kota di Povinsi Jawa Tengah tahun 2011-2017. Produk Domestik Regional Bruto (PDRB) merupakan variabel dependen, sedangkan variabel independen yang digunakan adalah jumlah infrastruktur pendidikan, jumlah infrastruktur kesehatan, panjang jalan raya provinsi, jumlah infrastruktur air bersih, dan jumlah hotel, penginapan dan restoran menggunakan pendekatan Random Effect Model (REM) karena terpilih sebagai model regresi data panel yang paling tepat. Hasil regresi secara parsial menyatakan bahwa Produk Domestik Regional Bruto (PDRB) dipengaruhi masing-masing secara signifikan dengan arah positif oleh jumlah infrastruktur pendidikan, jumlah infrastruktur kesehatan, panjang jalan raya provinsi, jumlah infrastruktur air bersih, dan jumlah hotel, penginapan dan restoran.
\end{abstract}

\section{AN ANALYSIS OF THE INFLUENCE OF THE BASIC SERVICE INFRASTRUCTURE \\ DEVELOPMENT, PROVINCIAL ROADS, CLEAN WATER, AND HOTEL, LODGING AND RESTAURANT ON GROSS REGIONAL DOMESTIC BRUTO}

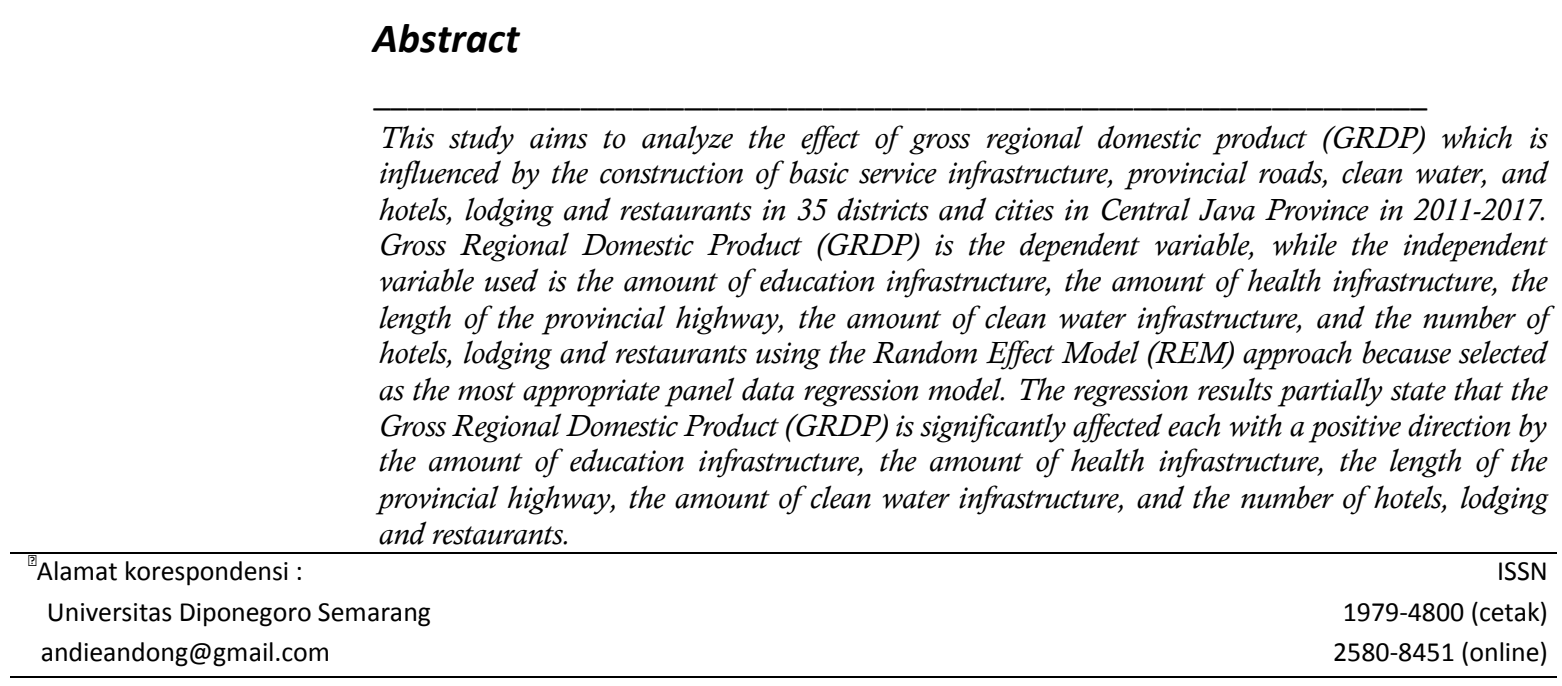




\section{PENDAHULUAN}

Pertumbuhan ekonomi merupakan salah satu indikator yang amat penting dalam melakukan analisis tentang pembangunan ekonomi yang terjadi pada suatu negara ataupun daerah. Salah satu faktor yang mendorong atau menghambat pertumbuhan ekonomi adalah pembangunan infrastrukturnya. Perekonomian negara atau suatu daerah berjalan tidak efisien manakala keadaan infrastrukturnya lemah. Biaya logistik menjadi sangat tinggi, daya saing menurun dan akan muncul ketidakadilan sosial.

Pembangunan infrastruktur dan aktivitas ekonomi memiliki hubungan timbal balik karena pembangunan infrastruktur menimbulkan ekspansi ekonomi melalui efek multiplier. Sedangkan ekspansi ekonomi menumbuhkan kebutuhan untuk memperluas infrastruktur yang ada untuk menyerap besarnya aliran barang dan jasa yang beredar atau bersirkulasi di seluruh perekonomian.

Dalam upaya mendukung tercapainya pertumbuhan ekonomi yang tinggi, pemerintah daerah sebagai otoritas pembangunan di daerah dituntut untuk menerapkan kebijakan yang dapat menciptakan iklim kondusif bagi kegiatan-kegiatan produktif para pelaku ekonomi. Salah satu kebijakan yang diperlukan untuk mencapai pertumbuhan ekonomi adalah dengan membangun infrastruktur dan mendorong terciptanya iklim investasi yang baik.

Simon Kuznet menyatakan bahwa "a countrys economics growth as a long term rise in capacity to supply increasingly diverse economic goods in its population, this growing capacity based on advancing technology and the institutional and ideological adjustments that's it demands" (Todaro, 2000).

Pertumbuhan suatu negara dipengaruhi oleh akumulasi modal (investasi pada tanah, peralatan, prasarana, dan sarana) sumber daya alam, sumber daya manusia baik jumlah maupun tingkat kualitas penduduknya, kemajuan teknologi, akses terhadap informasi, keinginan untuk melakukan inovasi dan mengembangkan diri serta budaya kerja (Todaro, 2000). Todaro (2000) menjelaskan kaitan infrastruktur dengan pembangunan ekonomi bahwa tercakup dalam pengertian infrastruktur yaitu aspek fisik dan finansial yang terkandung dalam jalan raya, kereta api, pelabuhan laut dan bentuk-bentuk sarana transportasi dan komunikasi ditambah air bersih, dan pelayanan publik lainnya dan fasilitas wisata seperti hotel dan restoran.

Berdasarkan data dari Badan Pusat Statistik (BPS) Jawa Tengah, pertumbuhan ekonomi Jawa Tengah dari tahun 2011 sampai tahun 2017 mengalami kenaikan. Rata-rata tiap tahun peningkatan di kisaran 5,29 persen selama dalam kurun waktu tersebut sebagaimana yang ditunjukkan pada Tabel 1 .

Tabel 1

Pertumbuhan PDB Jawa Tengah 2011-2017
\begin{tabular}{|c|r|}
\hline Tahun & Pertumbuhan \\
\hline $\mathbf{2 0 1 1}$ & 5,30 \\
\hline $\mathbf{2 0 1 2}$ & 5,34 \\
\hline $\mathbf{2 0 1 3}$ & 5,11 \\
\hline $\mathbf{2 0 1 4}$ & 5,27 \\
\hline $\mathbf{2 0 1 5}$ & 5,47 \\
\hline $\mathbf{2 0 1 6}$ & 5,25 \\
\hline $\mathbf{2 0 1 7}$ & 5,27 \\
\hline RATA-RATA & $\mathbf{5 , 2 9}$ \\
\hline
\end{tabular}

Sumber: BPS Provinsi Jawa Tengah, 2018, diolah

Perkembangan pertumbuhan ekonomi di Jawa Tengah dipengaruhi berbagai faktor, diantaranya adalah faktor pembangunan infrastruktur publik, yaitu infrastruktur pendidikan, 
infrastruktur kesehatan, infrastruktur jalan, infrastruktur air bersih, dan infrastruktur hotel, penginapan dan restoran.

Fasilitas pelayanan dasar seperti fasilitas pendidikan dan kesehatan jumlahnya relatif fluktuatif seperti yang ditunjukkan pada Tabel 2:

Tabel 2

Jumlah Infrastruktur Pendidikan di Jawa Tengah 2011-2017 (Unit)

\begin{tabular}{|c|c|c|c|c|c|c|c|}
\hline $\begin{array}{c}\text { Jenjang } \\
\text { Pendidika } \\
\mathbf{n}\end{array}$ & \multicolumn{7}{|c|}{ Tahun } \\
\cline { 2 - 8 } & $\mathbf{2 0 1 1}$ & $\mathbf{2 0 1 2}$ & $\mathbf{2 0 1 3}$ & $\mathbf{2 0 1 4}$ & $\mathbf{2 0 1 5}$ & $\mathbf{2 0 1 6}$ & $\mathbf{2 0 1 7}$ \\
\hline $\begin{array}{c}\text { SD } \\
\text { Sederajat }\end{array}$ & 23.316 & 23.282 & 23.126 & 23.115 & 23.740 & 22.488 & 22.538 \\
\hline $\begin{array}{c}\text { SMP } \\
\text { Sederajat }\end{array}$ & 4.574 & 5.370 & 5.057 & 5.023 & 5.159 & 4.887 & 4.898 \\
\hline $\begin{array}{c}\text { SMA } \\
\text { Sederajat }\end{array}$ & 2.572 & 3.610 & 2.771 & 2.940 & 3.019 & 2.860 & 2.867 \\
\hline JUMLAH & 30.462 & 32.262 & 30.954 & 31.078 & 31.285 & 29.636 & 29.701 \\
\hline
\end{tabular}

sumber: BPS Provinsi Jawa Tengah, 2018, diolah

Pada jumlah infrastruktur kesehatan pun dalam beberapa tahun mengalami fluktuasi, namun secara grafik masih meningkat. Peningkatan yang paling tinggi adalah pelayanan kesehatan yang berbasis masyarakat dan dikelola oleh desa yaitu pos pelayanan terpadu (posyandu) dan pos kesehatan desa (poskesdes) yang meningkat mulai tahun 2015 seperti yang ditunjukkan pada Tabel 3:

Tabel 3

Jumlah Infrastruktur Kesehatan di Jawa Tengah 2011-2017 (Unit)

\begin{tabular}{|c|r|r|r|r|r|r|r|}
\hline JENIS INFRASTRUKTUR & \multicolumn{7}{|c|}{ TAHUN } \\
\cline { 2 - 9 } KESEHATAN & $\mathbf{2 0 1 1}$ & $\mathbf{2 0 1 2}$ & $\mathbf{2 0 1 3}$ & $\mathbf{2 0 1 4}$ & $\mathbf{2 0 1 5}$ & $\mathbf{2 0 1 6}$ & $\mathbf{2 0 1 7}$ \\
\hline Rumah Sakit & 246 & 263 & 271 & 283 & 451 & 485 & 527 \\
\hline Puskesmas & 867 & 868 & 868 & 571 & 875 & 875 & 881 \\
\hline Posyandu & 291 & 306 & 307 & 318 & 48.615 & 48.831 & 48.891 \\
\hline Klinik & 1.837 & 1.827 & 1.827 & 1.827 & 973 & 1.166 & 1.310 \\
\hline Polindes & 948 & 948 & 948 & 948 & 5.866 & 5.931 & 5.975 \\
\hline JUMLAH & $\mathbf{4 . 1 8 9}$ & $\mathbf{4 . 2 1 2}$ & $\mathbf{4 . 2 2 1}$ & $\mathbf{3 . 9 4 7}$ & $\mathbf{5 6 . 7 8 0}$ & $\mathbf{5 7 . 2 8 8}$ & $\mathbf{5 7 . 5 8 4}$ \\
\hline
\end{tabular}

Sumber: BPS Provinsi Jawa Tengah, 2018, diolah

Dalam hal infrastruktur jalan raya, panjang jalan di Jawa Tengah yang berstatus jalan provinsi tidak banyak mengalami perkembangan, bahkan pada tahun 2016 dan 2017 mengalami penurunan drastis seperti yang ditunjukkan pada Tabel 4. Hal ini terjadi karena banyak yang beralih status menjadi jalan nasional maupun jalan kabupaten dan kota.

Tabel 4

Panjang Infrastruktur Jalan Provinsi 
Tahun 2011-2017 (Kilometer)

\begin{tabular}{|c|r|}
\hline Tahun & Panjang Jalan \\
\hline 2011 & $26.623,32$ \\
\hline 2012 & $26.737,25$ \\
\hline 2013 & $27.038,55$ \\
\hline 2014 & $26.412,00$ \\
\hline 2015 & $26.412,00$ \\
\hline 2016 & $2.397,74$ \\
\hline $2017^{*}$ & $2.404,76$ \\
\hline
\end{tabular}

Sumber: BPS Provinsi Jawa Tengah, 2018, diolah

Jumlah sambungan air bersih dari berbagai perusahaan daerah air minum (PDAM) yang beroperasi di seluruh kabupaten dan kota di Jawa Tengah juga kurang begitu pesat prekembangannya, terutama pada tahun 2015 sampai 2017 praktis tidak ada penambahan sambungan baru seperti yang ditunjukkan pada Tabel 5:

Tabel 5

Jumlah Infrastruktur Air Bersih di Jawa Tengah Tahun 2011-2017 (Unit Sambungan)

\begin{tabular}{|r|r|}
\hline Tahun & Jumlah Sambungan \\
\hline 2011 & 219.967 .694 \\
\hline 2012 & 243.057 .962 \\
\hline 2013 & 365.814 .531 \\
\hline 2014 & 313.978 .323 \\
\hline 2015 & 370.823 .153 \\
\hline 2016 & 370.823 .153 \\
\hline 2017 & 370.823 .153 \\
\hline
\end{tabular}

Sumber: Bappeda Jawa Tengah, 2018, diolah

Sedangkan infrastruktur hotel, penginapan dan restoran secara umum perkembangannya baik, hampir tiap tahun terjadi kenaikan sebagaimana ditunjukkan pada Tabel 6 .

Tabel 6

Jumlah Infrastruktur hotel, penginapan dan restoran di Jawa Tengah

Tahun 2011-2017 (Unit)

\begin{tabular}{|c|c|c|c|c|c|c|c|}
\hline Jenis & 2011 & 2012 & 2013 & 2014 & 2015 & 2016 & 2017 \\
\hline Hotel dan Penginapan & 1.351 & 1.441 & 1.463 & 1.528 & 1.533 & 1.627 & 1.958 \\
\hline Restoran & 1.583 & 3.442 & 3.642 & 5.368 & 5.478 & 3.045 & 5.526 \\
\hline Jumlah & $\mathbf{2 . 9 3 4}$ & $\mathbf{5 . 0 8 3}$ & $\mathbf{6 . 8 3 1}$ & $\mathbf{7 . 0 0 6}$ & $\mathbf{7 . 2 0 1}$ & $\mathbf{7 . 1 5 3}$ & $\mathbf{7 . 4 8 4}$ \\
\hline
\end{tabular}

sumber: BPS Provinsi Jawa Tengah, 2018, diolah

\section{TELAAH PUSTAKA}




\section{Pertumbuhan Ekonomi}

Pertumbuhan ekonomi adalah ekspansi yang secara terus menerus dari kemungkinan produksi di suatu negara yang diakibatkan dari akumulasi kapital dan perubahan teknologi. Model pertumbuhan Solow (Mankiw, 2003) menyatakan bahwa model pertumbuhan menunjukkan pertumbuhan persediaan modal, pertumbuhan angkatan kerja dan kemajuan teknologi berinteraksi dalam perekonomian, serta bagaimana pengaruhnya terhadap output barang dan jasa suatu negara secara keseluruhan atau dapat dikatakan bahwa keseluruhan output barang dan jasa di suatu negara ditentukan oleh persediaan modal, angkatan kerja dan kemajuan teknologi yang digunakan. Robert Solow mengembangkan model pertumbuhan ekonomi yang disebut sebagai Model Pertumbuhan Solow. Model tersebut berangkat dari fungsi produksi agregat sebagai berikut (Dornbusch et al, 2008):

$$
\mathrm{Y}=\mathrm{Af}(\mathrm{K} . \mathrm{L}) \text {. }
$$

Dimana $\mathrm{Y}$ adalah output nasional (kawasan), $\mathrm{K}$ adalah modal (capital) fisik, $\mathrm{L}$ adalah tenaga kerja, dan A merupakan teknologi. $\mathrm{Y}$ akan meningkat ketika input $\mathrm{K}$ atau $\mathrm{L}$, atau keduanya meningkat. Faktor penting yang mempengaruhi pengadaan modal fisik adalah investasi. Output (Y) juga akan meningkat bila terjadi perkembangan dalam kemajuan teknologi yang terindikasi dari kenaikan A. Dijabarkan lagi fungsi pertumbuhan Solow dalam Mankiw (2012) dijabarkan lagi menjadi:

$\mathrm{Y}=\mathrm{F}(\mathrm{K}, \mathrm{L} \times \mathrm{E})$

Nilai E dalam fungsi di atas adalah efisiensi dari L atau tenaga kerja mencerminkan pengetahuan tentang metode produksi. Nilai efisiensi tenaga kerja akan meningkat bila terjadi peningkatan dalam bidang kesehatan dan pendidikan atau keahlian dari tenaga kerja tersebut. Oleh karena itu, pertumbuhan perekonomian dapat berasal dari pertumbuhan input, perkembangan kemajuan teknologi yang disebut juga sebagai pertumbuhan total faktor produktivitas dan efisiensi tenaga kerja.

Peran investasi, termasuk investasi infrastruktur, dalam aktivitas ekonomi dapat dipisahkan atas perannya sebagai komponen pengeluaran agregat dan perannya dalam proses produksi. Investasi merupakan bagian dari komponen pengeluaran agregat, sedangkan stok kapital fisik infrastruktur merupakan bagian dari faktor produksi dalam fungsi produksi sektoral atau agregat.

Berdasarkan kategori tersebut, penjelasan teoritis mengenai peran investasi akan dilihat dari sisi permintaan dalam sebuah model makro ekonomi dan sisi penawaran yang dipresentasikan oleh model pertumbuhan ekonomi. Pada bagian ini akan diuraikan teori sisi permintaan yaitu model ekonomi keynesian. Model ekonomi makro Keynesian merupakan teori yang menjelaskan fluktuasi ekonomi dalam jangka pendek dengan memfokuskan perhatiannya pada sisi pengeluaran agregat. Identitas produk nasional bruto (PNB) standar Keynesian dapat diilustrasikan sebagai berikut:

$\mathrm{C}+\mathrm{I}+\mathrm{G}+(\mathrm{X}-\mathrm{M})=\mathrm{PNB}=\mathrm{C}+\mathrm{S}+\mathrm{T}+\mathrm{Rf}$

Keterangan:

$\mathrm{C}$ : total pengeluaran konsumsi rumah tangga terhadap barang dan jasa

I : Investasi

$\mathrm{G}$ : pengeluaran pemerintah

(X-M) : ekspor bersih barang dan jasa

$\mathrm{S}$ : tabungan swasta bruto

$\mathrm{T}$ : penerimaan pajak bersih

Rf : total pembayaran transfer ke luar negeri 
Identitas di atas menunjukkan bahwa kondisi ekuilibrium dicapai ketika total pengeluaran agregat sama dengan total pendapatan agregat dan keduanya sama dengan total nilai produksi barang dan jasa akhir yang dihasilkan suatu perekonomian. Pada posisi keseimbangan, nilai ekspor bersih sama dengan total pembayaran ke luar negeri, sehingga kedua komponen ini dapat dikeluarkan untuk penyederhanaan identitas pendapatan nasional sebagai berikut:

$$
\mathrm{C}+\mathrm{I}+\mathrm{G}=\mathrm{PNB}=\mathrm{C}+\mathrm{S}+\mathrm{T}
$$

Seluruhnya komponen pengeluaran dan pendapatan agregat apabila dideflasikan terhadap tingkat harga umum yang berlaku, diperoleh identitas pendapatan nasional dalam nilai riil sebagai berikut:

$\mathrm{c}+\mathrm{i}+\mathrm{g}=\mathrm{y}=\mathrm{c}+\mathrm{s}+\mathrm{t}$

Keterangan:

$\begin{array}{ll}\mathrm{t}=\mathrm{t}^{\prime} \mathrm{y} ; & \mathrm{t}^{\prime}>0 \\ \mathrm{c}=\mathrm{c}^{\prime} \mathrm{yd} ; & \mathrm{c}^{\prime}>0 \\ \mathrm{~s}=\mathrm{s}^{\prime} \mathrm{yd} ; & \mathrm{s}^{\prime}>0 \\ \mathrm{i}=\mathrm{i} & \\ \mathrm{g}=\mathrm{g} & \\ \mathrm{yd}=\mathrm{y}-\mathrm{ty} ; & \end{array}$

Pada persamaan penerimaan pajak (t), total pengeluaran konsumsi (c) dan total tabungan (s) semuanya mcrupakan fungsi tingkat pendapatan, dengan kecenderungan tambahan pajak ( $\left.\mathrm{t}^{\prime}\right)$ atau marginal propensity to tax (MPT), kecenderungan tambahan konsumsi (c') atau marginal propensity to consume (MPC) dan kecenderungan tambahan tabungan (s') atau marginal propensity to save (MPS) positif tetapi lebih kecil dari satu. Pada persamaan investasi swasta (i) dan pengeluaran pemerintah ( $\mathrm{g}$ ) diasumsikan sebagai faktor eksogenus.

Seluruh komponen pengeluaran agregat apabila disubsitusikan ke sisi pengeluaran pada persamaan asal akan diperoleh pengeluaran agregat riil sebagai berikut :

yc $(y-t y)+i+g$

Derivasi total pendapatan nasional, y, terhadap komponen c, t, g, dan i pada persamaan di atas dan menyusunnya kembali akan menghasilkan efek pengganda (multiplier) pendapatan dari perubahan faktor eksogenus investasi swasta dan pengeluaran pemerintah sebagai berikut:

$$
d y=\frac{1}{1-c(1-t)}(d \bar{i}+d \bar{g})
$$

Pada persamaan di atas, setiap perubahan faktor eksogenus investasi swasta dan pengeluaran pemerintah akan mengakibatkan perubahan pendapatan nasional sebesar hasil kali angka pengganda dengan kenaikan komponen pengeluaran tersebut. Besarnya dampak kenaikan investasi dan pengeluaran pemerintah tersebut tergantung pada MPC dan MPT, semakin besar MPC dan semakin kecil MPT maka semakin besar dampat perubahannya terhadap pendapatan nasional.

Pada model Domar, dinyatakan bahwa perumbuhan permintaan agregat sama dengan investasi (I) dikalikan dengan besaran multiplier (1/s). Sedangkan pertumbuhan kapasitas produksi (penawaran agregat) sama dengan investasi dibagi rasio kapital output (k). Menurut Harrod, pertumbuhan ekonomi dapat dibedakan atas pertumbuhan aktual. pertumbuhan yang diinginkan dan pertumbuhan alamiah. Pertumbuhan aktual (the actual growth $=\mathrm{AY} / \mathrm{Y}$ ) adalah 
laju pertumbuhan sesungguhnya yang besarnya ditentukan oleh rasio tabungan-output $(\mathrm{S} / \mathrm{Y})$ dan rasio tambahan kapital-output (AK/AY). Kedua besaran dianggap konstan dan melalui manipulasi matematis akan sama dengan tabungan. Pada tingkat laju pertumbuhan aktual. output aktual tidak sama dengan output potensial.

Laju pertumbuhan yang diinginkan adalah laju pertumbuhan yang dianggap memadai oleh para investor, sehingga menjamin tercapainya kapasitas penuh atau keseimbangan permintaan dan produksi dalam jangka panjang. Permintaan agregat dianggap cukup tinggi oleh para investor pada laju pertumbuhan ini sehingga dapat menjamin terjualnya seluruh kapasitas pabrik yang ada. Output aktual dalan sama dengan output potensial sehingga tidak terjadi variasi siklis dalam pertumbuhan ekonomi. Laju pertumbuhan ini tercapai apabila output (aktual dan potensial), permintaan agregat, stok kapital, dan investasi tumbuh pada tingkat yang sama.

\section{Produk Domestik Regional Bruto (PDRB)}

Keseluruhan produk barang dan jasa yang diproduksi pada suatu waktu diperlukan pengukuran karena barang dan jasa yang diproduksi tetap yang mempunyai nilai ekonomi pada level makro disebut sebagai Gross Domestic Product (GDP). GDP is the aggregate value of all final goods and services product in the economic during a given time period - ussualy a year (Taggart et.al: 2003). GDP adalah nilai agregat dari keseluruhan produk barang dan jasa final dalam perekonomian selama suatu jangka waktu tertentu biasanya satu tahun. Cukup jelas terlihat bahwa pertumbuhan perekonomian suatu negara diperlihatkan oleh seberapa besar peningkatan GDP negara yang bersangkutan. GDP menjadi salah satu indikator pertumbuhan perekonomian yang cukup penting untuk menilai laju pertumbuhan ekonomi demi peningkatan kesejahteraan ekonomi masyarakat.

Pengukuran produk domestik lazimnya dilakukan dalam ukuran kotor (gross) karena mengabaikan adanya depresiasi (penurunan harga tahunan) sebagai efek domino inflasi. Produk domestik biasanya dikuantifikasikan dalam bentuk GDP

GDP berkaitan dengan apa, dimana dan kapan produksi itu dilakukan. GDP juga dapat diukur melalui pendekatan pendapatan. Asumsi dasarnya adalah pendapatan seseorang diukur dari apa yang diproduksinya. Posisi setiap orang sebagai tenaga kerja adalah penentu pertumbuhan ekonomi. GDP memang pendapatan tenaga kerja secara totalitas dalam lingkup nasional. Artinya, GDP mencerminkan keseluruhan pendapatan yang diperoleh semua orang di semua lapangan pekerjaan yang memproduksi barang jasa yang diukur melalui besaran nilai uang. Demikianlah cara berpikir GDP melalui pendekatan pendapatan.

Menurut Mankiw (2003), GDP adalah pendapatan total yang diperoleh secara domestik, termasuk pendapatan yang diperoleh faktor-faktor produksi yang dimiliki asing: pengeluaran total atas barang dan jasa yang diproduksi secara domestik. GDP yang lazim diukur dalam rentang satu tahun. Selama waktu tertentu dapat saja berfluktuasi menaik atau menurun karena banyak sebab. Untuk lebih meyakinkan tentang besaran GDP yang sesungguhnya dilakukan pengukuran beberapa tahun selama jangka waktu tertentu. Angka rata-rata yang didapat setelah dilakukan pengukuran GDP selama jangka waktu tertentu menjadi real GDP dan menjadi lebih dipercaya dibanding GDP untuk satu tahun.

\section{Infrastruktur}

Fasilitas infrastruktur dipahami sebagai input infrastruktural publik dari sudut pandang suplai. Namun, dilihat dari sifat pelayanan yang diberikan, infrastruktur secara luas dapat digolongkan menjadi kategori fisik, sosial dan finansial. Kategori fisik meliputi transportasi (rel kereta, jalan, jalur udara, dan jalur perairan), listrik, irigasi, telekomunikasi, suplai air dan sebagainya. Meskipun pengaruhnya bersifat langsung terhadap produksi melalui ekonomi 
eksternal, namun aspek tersebut berpengaruh pula secara menguntungkan dalam menarik investasi swasta (domestik dan asing). Infrastruktur fisik berkontribusi terhadap pertumbuhan ekonomi dengan cara mengurangi biaya transaksi dan menciptakan banyaknya investasi, lapangan kerja, hasil (output), pendapatan dan pertumbuhan sampingan. Infrastruktur sosial berkontribusi melalui pengayaan sumber daya manusia dalam hal pendidikan, kesehatan, perumahan, fasilitas rekreasi dan sebagainya. Dengan kata lain, infrastruktur sosial ditujukan untuk memajukan kualitas hidup. Infrastruktur ini berpengaruh terhadap tingginya sumber daya manusia dalam hal kualitas dan membantu meningkatkan produktivitas pekerja. Selanjutnya, infrastruktur finansial yang meliputi kerjasama perbankan, pos dan pajak dari warga negara yang mewakili kinerja finansial negara. Tiga aspek ini mewakili kemampuan menciptakan penghasilan dari suatu daerah dalam suatu negara atau suatu negara dalam suatu wilayah.

Ghosh (2005) mengamati pengaruh ekonomi dari infrastruktur publik di Jepang dengan meluaskan definisi Hansen yang menambah sistem komunikasi. Dia menyatakan bahwa tidak adanya fasilitas tersebut dalam satu wilayah akan mengakibatkan berkurangnya "efisiensi produktif" dari suatu masyarakat. Infrastruktur tersebut merupakan sejumlah karakteristik yang sangat substansial yang membedakan negara-negara saat ini.

\section{Hubungan antara Infrastruktur dan Pertumbuhan Ekonomi}

Easterly dan Rebelo (1993) menemukan pengaruh positif investasi di bidang transportasi terhadap pertumbuhan ekonomi. Jayme Jr. et al, (2009) menyatakan dalam penelitiannya bahwa pengeluaran di bidang infrastruktur berpengaruh secara positif terhadap kinerja makro ekonomi suatu negara. Kenaikan biaya pengeluaran di bidang infrastruktur mengurangi biaya produksi perusahaan dan sebagai konsekuensinya, menstimulasi investasi, produktivitas dan pertumbuhan ekonomi. Argumen yang ada adalah pemerintah tidak menciptakan lapangan kerja secara langsung, namun membantu menciptakan suasana kondusif dalam investasi swasta dan produksi pada level yang kompetitif. Dengan kata lain, investasi publik memiliki potensi untuk menstimulasi investasi swasta. Sebagai kesimpulan, peningkatan dalam pengeluaran publik yaitu di bidang infrastruktur untuk sektor-sektor strategis terutama transportasi adalah sesuatu yang penting dan produktif.

Penelitian Ghosh (2005) menjelaskan bahwa pengaruh utama dari jalan di pedesaan memang tidak tertuju pada infrastruktur swasta, namun melalui marketing dan distribusi dan juga melalui pengurangan biaya transaksi pada komoditas pertanian. Sementara listrik dan infrastruktur pedesaan lainnya memiliki pengaruh langsung terhadap investasi swasta dalam pompa elektris.

Menggunakan infrastruktur fisik dan sosial menunjukkan bahwa penurunan biaya produksi dalam manufaktur diakibatkan dari investasi infrastruktur. Dalam studi yang lebih mendetail membuktikan bahwa suatu daerah yang memulai dengan infratruktur dan SDM yang lebih baik dibanding lain memiliki tingkat penurunan kemiskinan yang jangka panjang (Ghosh, 2005).

Menurut Ghosh (2005), dengan menggunakan fasilitas infrastrukur pada negara Asia Selatan selama dua dekade, perbedaan dana dalam infrastruktur fisik bertanggung jawab pada naiknya perbedaan secara regional. Dengan menggunakan pendekatan fungsi produksi, disimpulkan bahwa transportasi, listrik, gas dan suplai air, dan fasilitas komunikasi memiliki efek positif terhadap pertumbuhan ekonomi dan secara simultan memiliki pendapatan dengan skala yang meningkat. Pembangunan fasilitas infrastruktur tambahan di tahap awal dapat memiliki pengaruh positif secara langsung terhadap pendapatan.

Pendapat Ghosh di atas diperkuat oleh Fogel (dalam Suminar dkk., 2016), bahwa khusus di negara-negara berpenghasilan rendah, kondisi kesehatan dan pendidikan yang rendah, menghadapi tantangan yang lebih berat untuk mencapai pertumbuhan yang berkelanjutan jika 
dibandingkan dengan negara yang lebih baik keadaan kesehatan dan pendidikannya. Peningkatan kesejahteraan ekonomi sebagai akibat dari bertambah panjangnya usia sangatlah penting.

Berkaitan dengan pertumbuhan ekonomi, pendidikan erat kaitannya dengan kualitas angkatan kerja dan mekanisme lain di samping perkembangan teknologi yang meningkatkan pendapatan per kapita (Manfred, 2006). Lebih jauh lagi menurut Manfred, sektor pendidikan ini masuk dalam investasi sektor publik yang masuk dalam belanja pemerintah di samping infrastruktur yaitu jalan raya dan jalan rel serta sistem legal. Senada dengan yang diutarakan Manfred, Jochumsen (2010) menyatakan bahwa pelayanan kesehatan, pendidikan dan pertahanan keamanan masuk dalam belanja pemerintah. Sehubungan dengan peran infrastruktur pendidikan, Mankiw (2012) menyebutkan bahwa negara dengan PDB tinggi per orangnya pasti akan memiliki skala tinggi di berbagai aspek kehidupan, seperti mobil, rumah, literasi, pelayanan kesehatan, harapan hidup, dan sambungan internet dengan jumlah banyak, karena menurut Jochumsen, bahwa pendidikan dan peningkatan human capital adalah aspek penting dalam peningkatan PDB.

Pertumbuhan ekonomi menurut Doepke dkk (1999) tidak terlepas dari faktor human capital yang salah satu di antara bagian dari human capital tersebut adalah pendidikan angkatan kerja. Budirahmayani dan Khoirunurrofik (2019) menyatakan bahwa dalam hal sarana pariwisata yaitu hotel baik yang berbintang atau non bintang, termasuk penginapan dapat meningkatkan PDB yang dalam konteks regional sama dengan PDRB. Sebelumnya pada tahun 2015, Čerović dkk (2015) dalam penelitiannya di wilayah Balkan Barat menyatakan bahwa industri wisata yang terdiri dari hotel dan restoran menyumbang kontribusi positif dan signifikan terhadap PDB. Antara dan Sumarniasih (2017) menyatakan bahwa sejauh ini, tidak ada istilah sektor pariwisata di sektor Produk Domestik Bruto (PDB), jika pariwisata diwakili oleh sektor perdagangan, hotel dan restoran, kontribusi pariwisata terhadap perekonomian Bali (Gross Produk Regional Domestik, PDRB) sebesar 27,82 persen pada tahun 2010 meningkat menjadi 31,35 persen pada tahun 2014. Temuan yang sama terlebih dahulu dikemukakan berdasarkan hasil penelitian FaladeObalade dan Dubey (2014) yang menyatakan pariwisata adalah industri yang mirip dengan industri lain yang menghasilkan pendapatan dan berkontribusi terhadap PDB dan neraca pembayaran suatu negara. Industri pariwisata tersebut menurut FaladeObalade dan Dubey (2014) sektor swasta dalam industri pariwisata diwakili oleh hotel dan perusahaan manajemen perhotelan dan sektor layanan lainnya.

\section{METODE}

Data yang digunakan dalam penelitian ini, yaitu data sekunder yang bersumber pada laporan Badan Pusat Statistik (BPS) Jawa Tengah dan Badan Perencanaan Pembangunan Daerah (Bappeda) Jawa Tengah. Jenis data yang digunakan adalah data panel yaitu gabungan time series dan cross section. Data time series periode tahun 2011-2017 sedangkan data cross section adalah 35 kabupaten dan kota di Jawa Tengah.

\section{Variabel Penelitian}

Variabel independen/bebas pada penelitian ini antara lain:

a. Infrastruktur Pendidikan (INFPENDit): jumlah gedung sekolah untuk pendidikan formal dari tingkat sekolah dasar (SD) yaitu SD dan Madrasah Ibtidaiyah (MI) sampai dengan Sekolah Lanjutan Tingkat Atas (SLTA) baik Sekolah Menengah Atas (SMA), 
Sekolah Menengah Kejuruan (SMK) dan Madrasah Aliyah (MA) di seluruh Jawa Tengah baik yang dikelola pemerintah maupun swasta dengan satuan unit

b. Infrastruktur Kesehatan (INFKESit): jumlah seluruh rumah sakit (RS), rumah bersalin, klinik termasuk milik swasta, pusat kesehatan masyarakat (puskesmas), pos pelayanan terapdu (posyandu) dan pos kesehatan desa (poskesdes) di 35 kabupaten dan kota di Jawa Tengah dengan satuan unit

c. Infrastuktur Jalan (INFJit): jumlah keseluruhan panjang jalan yang berstatus jalan provinsi yang tersebar di seluruh Provinsi.

d. Air Bersih (INFABit): jumlah seluruh sambngan air minum yang diusahakan seluruh Perusahaan Daerah Air Minum (PDAM) di seluruh kabupaten/kota di Jawa Tengah dari berbagai klasifikasi baik tempat tinggal, usaha, sosial dan industri dengan satuan sambungan

e. Infrastruktur Hotel, Penginapan dan Restoran (INFHPRit): jumlah seluruh hotel dan penginapan dari berbagai jenis hotel dan kelas yang tersebar di seluruh Provinsi Jawa Tengah. Satuan yang digunakan adalah unit.

Variabel dependen adalah variabel yang besarannya dipengaruhi oleh variabel lain. Variabel dependen dari penelitian ini yaitu Pertumbuhan Ekonomi (Yit) yang dihitung dari Produk Domestik Regional Bruto (PDRB) 35 kabupaten dan kota di Provinsi Jawa Tengah. Satuan yang digunakan adalah rupiah (Rp).

\section{Metode Analisis Data}

Metode analisis data dimulai dari uji pemilihan model, antara lain:

Tabel 7

Ringkasan Hasil Uji Pemilihan Model

\begin{tabular}{|c|c|c|}
\hline $\begin{array}{c}\text { Jenis Uji } \\
\text { Pemilihan } \\
\text { Model }\end{array}$ & Hasil & Model Dipilih \\
\hline Uji Chow & $\begin{array}{l}\text { Prob. F, } \\
\text { menunjukkan } \\
\text { hasil kurang } \\
\text { dari } 0,05 \\
\text { (terestimasi } \\
0,0004 \text { ) }\end{array}$ & Fixed effect \\
\hline $\begin{array}{l}\text { Uji Spesifikasi } \\
\text { Hausman }\end{array}$ & Prob. 0,0000 & $\begin{array}{l}\text { ECM atau random } \\
\text { effect }\end{array}$ \\
\hline $\begin{array}{l}\text { Uji Lagrange } \\
\text { Multiplier } \\
\text { Breausch-Pagan }\end{array}$ & $\begin{array}{l}\text { probability chi- } \\
\text { square di bawah } \\
0,05 \text { (terstimasi } \\
0,0000 \text { ) }\end{array}$ & $\begin{array}{l}\text { ECM atau random } \\
\text { effect }\end{array}$ \\
\hline
\end{tabular}

Sumber: data diolah 
Dengan berdasarkan ketiga uji yang diringkas dalam tampilan Tabel 7 tersebut maka spesifikasi model regresi linear berganda menggunakan pendekatan random effect. sehingga muncul persamaan regresi:

PDRBit $=\beta 1+\beta 2$ INFPENDit $+\beta 3$ INFKESit $+\beta 4$ INFJit $+\beta 5$ INFABit $+\beta 6$ INFHPRit

$+\mu$

Di mana:

PDRB : Produk Domestik Regional Bruto

INFPEND : Infrastruktur Pendidikan

INFKES : Infratruktur Kesehatan

INFJ : Infrastruktur Jalan Raya

INFAB : Infrastruktur Air Bersih

INFHPR : Infrastruktur Hotel, Penginapan dan Restoran

$\mu \quad$ : Kesalahan pengganggu

i : Banyaknya kabupaten/kota

t : Banyaknya tahun

\section{Pengujian Statistik Analisis Regresi:}

Uji Signifikasi dalam penelitian ini meliputi :

1. Uji Asumsi Klasik

Istilah multikolinearitas menurut Gujarati dan Porter (2013) adalah hubungan secara linear di antara variabel Xi. Multikolinearitas terjadi bila terlihat korelasi antar variabel independen bernilai tinggi. Nilai korelasi melebihi 0,8 berarti terjadi multikolinearitas serius (Gujarati dan Porter, 2013).

Uji Heteroskedastisitas digunakan untuk mengetahui kesamaan varian variabel terpengaruh Y (Gujarati dan Porter. 2013). Cara mengetahui adanya heteroskedastisitas menggunakan cara formal maupun informal. Cara formal yang akan digunakan adalah uji glejser karena uji ini banyak digunakan pada sampel besar, walaupun dapat juga digunakan untuk sampel kecil dan Glejser menyarankan meregresikan nilai residual absolut pada variabel X yang dianggap berasosiasi dekat dengan $\square$ (Gujarati dan Porter, 2013).

2. Koefisien Determinasi

Suatu R2 sebesar 1 berarti suatu kecocokan sempurna, sedangkan R2 sebesar 0 berarti tidak ada hubungan antara variabel terpengaruh dengan variabel pengaruh (Gujarati dan Porter, 2013).

3. Uji Parsial (Uji t)

Uji t digunakan untuk menguji sebuah hipotesis terhadap koefisien masing-masing regresi secara parsial (Gujarati dan Porter, 2013)

4. Uji Simultan (Uji F)

Uji Statistik F menguji apakah semua variabel pengaruh atau bebas yang dimasukkan dalam model mempunyai pengaruh secara bersama-sama terhadap variabel terpengaruh (Gujarati dan Porter, 2013). 


\section{HASIL DAN PEMBAHASAN}

1. Uji Asumsi Klasik

Cara menguji keberadaan multikolinearitas dengan mengkorelasikan masing-masing peubah/variabel bebas dengan sesamanya tanpa mengikutsertakan variabel terikat sebagaimana yang ditunjukkan pada Tabel 8 .

Tabel 8

Hasil Korelasi Antar Variabel Bebas

\begin{tabular}{|c|r|r|r|r|c|}
\hline & \multicolumn{1}{|c|}{ INFPEND } & \multicolumn{1}{c|}{ INFKES } & \multicolumn{1}{c|}{ INFJ } & \multicolumn{1}{|l}{ INFAB } & \multirow{2}{*}{ INFHPR } \\
\hline INFPEND & 1.000000 & 0.247829 & 0.353763 & 0.087086 & 0.278532 \\
\hline INFKES & 0.247829 & 1.000000 & -0.358642 & 0.065306 & 0.135503 \\
\hline INFJ & 0.353763 & -0.358642 & 1.000000 & 0.123317 & 0.079682 \\
\hline INFAB & 0.087086 & 0.065306 & 0.123317 & 1.000000 & 0.069739 \\
\hline INFHPR & 0.278532 & 0.135503 & 0.079682 & 0.069739 & 1.000000 \\
\hline
\end{tabular}

Sumber: Hasil olah data menggunakan Eviews 9, 2020

Multikolinearitas terjadi bila terlihat korelasi antar variabel independen bernilai tinggi. Nilai korelasi melebihi 0,8 berarti terjadi multikolinearitas serius (Gujarati dan Porter. 2013). Hasil uji multikolinearitas dengan korelasi antar variabel independen jauh di bawah 0,8 (tertinggi antara INFJ dan INFPEND senilai 0,353763) berarti tidak terdapat multikolinearitas.

Cara mendeteksi heteroskedastisitas adalah dengan melakukan uji Glesjer (Basuki dan Yuliadi, 2015) yang hasilnya ditunjukkan pada Tabel 9.

Tabel 9

Hasil Uji Multikolinearitas Glesjer

\begin{tabular}{|c|r|}
\hline Variabel Dependen & ABS(RESID01) \\
\hline Variabel & Prob. \\
\hline C & 0.6781 \\
\hline INFPEND & 0.6281 \\
\hline INFKES & 0.0004 \\
\hline INFJ & 0.2983 \\
\hline INFAB & 0.0000 \\
\hline INFHPR & 0.8117 \\
\hline
\end{tabular}

Sumber: Hasil olah data menggunakan Eviews 9, 2020

Pada regresi untuk Uji Glesjer, terdapat 2 variabel yang signifikan pada $p=0,05$ yaitu variabel INFKES dan INFAB sehingga berdasarkan Uji Glesjer, persamaaan ini bermasalah dengan homoskedastisitas. Menurut Basuki (Basuki dan Yuliadi. 2014) karena model tidak lolos Heteroskedastisitas maka model dibuat log. Variabel yang dapat di-log-kan yaitu variabel PDRB karena satuannya yang digunakan adalah beda sendiri yaitu Rp sedangkan 
variabel dependent-nya semuanya adalah unit atau yang dipersamakan dengan unit yaitu sambungan pada variabel air, maka muncul persamaan regresi baru yaitu:

$\log ($ PDRBit $)=\beta 1+\beta 2$ INFPENDit $+\beta 3$ INFKESit $+\beta 4$ INFJit $+\beta 5$ INFABit $+\beta 6$

INFHPRit $+\mu$

2. Koefisien Determinasi

Nilai koefisien determinasi Adjusted R-squared (direkomendasikan untuk penggunaan regresi berganda) sebagaimana ditunjukkan pada Tabel 10. adalah 0,616338 jadi kelima variabel indepenten tersebut hanya mampu menjelaskan sebanyak 0,616338 saja sedangkan sisanya 0,383662 dijelaskan variabel-variabel lain di luar persamaan.

Tabel 10

Weighted Statistic

\begin{tabular}{|c|c|}
\hline$R$-squared & 0.616338 \\
\hline Adjusted $R$-squared & 0.608312 \\
\hline F-statistic & 76.78885 \\
\hline Prob(F-statistic) & 0.000000 \\
\hline
\end{tabular}

Sumber: Hasil olah data menggunakan Eviews 9, 2020

3. Uji Parsial (Uji t)

Acuan untuk hasil uji parsial, berdasarkan hasil penghitungan menggunakan Eviews 9, yang ditampilkan pada Tabel 11.

Tabel 11

Hasil Uji Parsial

\begin{tabular}{|c|c|c|c|}
\hline \multicolumn{4}{|l|}{ Variabel Dependen: LOG(PDRB) } \\
\hline Metode: Panel EGLS (Cross-section random effects) \\
\hline Variabel & Koefisien & t-Statistik & \multicolumn{1}{c|}{ Prob. } \\
\hline C & 43.21359 & 606.2600 & 0.0000 \\
\hline INFPEND & 0.000649 & 7.452902 & 0.0000 \\
\hline INFKES & 0.000127 & 3.694140 & 0.0003 \\
\hline INFJ & 0.000195 & 2.823960 & 0.0051 \\
\hline INFAB & $2.39 E-08$ & 11.02001 & 0.0000 \\
\hline INFHPR & 0.000421 & 6.618221 & 0.0000 \\
\hline
\end{tabular}

Sumber: Hasil olah data menggunakan Eviews 9, 2020

Berdasarkan hasil uji parsial sebagaimana ditunjukkan pada Tabel 11 di atas dapat disimpulkan sebagai berikut:

a. Dalam uji hubungan variabel secara parsial pengaruh infrastruktur pendidikan (INFPEND) terhadap PDRB di Jawa Tengah tahun 2011-2017 adalah signifikan positif. Hasil tersebut sesuai dengan hasil penelitian yang pernah dilakukan Mariyatul Kubtiyah Ritonga (2014), Hasti Aringga Suminar dkk (2016), Agung Budi Luhur Wibowo (2016), Rusmusi IMP dan Dita Resmi Handayani (2018) dan Lise Pranessy dkk (2018). Koefisien variabel INFPHR senilai 0,000649 yang berarti peningkatan 0,000649 rupiah PDRB karena penambahan 1 unit infrastruktur pendidikan apabila variabel lain tidak berubah. Penyebab ini bila dirunut dari 
perkembangan jumlah fasilitas pendidikan secara agregat maka pernah terjadi penurunan pada 2013 dan 2016 sementara PDRB semakin naik dari tahun ke tahun. Fluktuatifnya jumlah sarana pendidikan ketika diamati di lapangan adalah karena fenomena kekurangan murid sehingga beberapa sekolah harus di-merger seperti yang penulis pernah temui di Jepara, Grobogan dan Pekalongan pada jenjang pendidikan sekolah dasar. Beberapa faktor lain adalah pengusahaan sekolah oleh swasta terutama oleh sekelompok masyarakat berbasis agama seperti Sekolah Dasar Islam Terpadu (SDIT) dan Sekolah Menengah Pertama Islam Terpadu (SMPIT) yang sepengamatan pada kurun waktu 2017 menambah jumlah fasilitas pendidikan walaupun fenomena tersebut mayoritas terjadi di kota-kota besar dan daerah-daerah dengan tingkat perekonomian cukup pesat karena ghiroh atau semangat primordialisme berdasarkan agama justru semakin kuat. Tawaran solusi agar pengaruh infrastruktur pendidikan terhadap PDRB semakin besar adalah dengan menjadikan produk dari pendidikan itu siap untuk berproduksi yaitu dengan memperbanyak sekolah kejuaruan/SMK kemudian menyalurkan ke pemberi kerja.

b. Dalam uji hubungan variabel secara parsial pengaruh infrastruktur kesehatan (INFKES) terhadap PDRB di Jawa Tengah tahun 2011 - 2017 adalah signifikan positif. Hasil tersebut sesuai dengan hasil penelitian yang pernah dilakukan oleh Mariyatul Kubtiyah Ritonga (2014), Hasti Aringga Suminar dkk (2016), Agung Budi Luhur Wibowo (2016), Ema Noviyanti Aminah (2017), Lise Pranessy dkk (2018) dan yang terakhir oleh Fatimah At-Thohiroh (2018). Koefisien regresi variabel INFKES senilai 0,000126 yang artinya peningkatan 0,000126 rupiah PDRB karena penambahan 1 unit infrastruktur kesehatan bila faktor lainnya tetap. Bila dilihat dari data infrastruktur kesehatan pada Tabel 1.5 peningkatan pesat justru terjadi di jenis infrastruktur posyandu yang paling berkembang pesat dan poliklinik desa atau polindes dari tahun 2015 sebagaimana dibahas pada Bab IV. Hal ini patut diduga karena desa-desa mendapat bantuan lebih banyak termasuk karena program dana desa yang mulai berlaku akhir 2015. Solusi agar menaikkan PDRB dari sisi fasilitas kesehatan yaitu dengan memberikan fasilitas layanan kesehatan dengan kualitas lebih hingga ke desa-desa yaitu dengan memanfaatkan dana desa dari pusat yang dalam hal ini adalah dari sisi regulasi agar pemanfaatan dana desa untuk layanan kesehatan lebih ditingkatkan. Solusi kedua adalah bantuan Pemerintah Provinsi terutama yang bidang ketahanan masyarakat perlu digeser penggunaannya ke layanan kesehatan.

c. Hasil uji hipotesis parsial untuk infrastruktur jalan (INFJ) menunjukkan bahwa terdapat pengaruh signifikan INFJ terhadap PDRB di Jawa Tengah pada kurun waktu 2011-2017. Hasil tersebut sesuai hasil kajian Rindang Bangun Prasetyo dan Muhammad Firdaus (2009), Hasti Aringga Suminar dkk (2016), Agung Budi Luhur Wibowo (2016), dan Rusmusi IMP dan Dita Resmi Handayani (2018), Fatimah AtThohiroh (2018) Lise Pranessy dkk (2018) dan yang terakhir oleh Azuwandri dkk (2019). Nilai koefisien regresi variabel INFJ adalah 0,000195 yang artinya peningkatan 0,000195 rupiah PDRB karena penambahan 1 kilometer jalan Provinsi kalau variabel yang lainnya tetap. Pengaruh yang kecil tersebut disebabkan karena panjang jalan provinsi relatif tidak berubah dari tahun ke tahun (Tabel 1.6) sebentara PDRB nilainya tiap tahun-semakin bertambah. Patut diduga pengaruh yang kecil 
tersebut karena memang Provinsi tidak membangun jalan baru tetapi dengan keberadaan Toll Trans Jawa yang beroperasi penuh sejak 2016 menjadi semakin pesatnya pertumbuhan ekonomi dan jalan tol tersebut bukan merupakan aset Pemprov Jateng, namun hal ini membuka baru peluang penelitian baru untuk memasukkan panjang jalan tol yang melalui Jawa Tengah dengan pertumbuhan ekonomi atau menggunakan variabel jalan secara keseluruhan. Solusi dari sisi infrastruktur jalan adalah selain memperbaiki kualitas yang sekarang sudah dan sedang dilakukan yaitu dengan cara membangkitkan ekonomi masyarakat di sekitar jalan-jalan provinsi agar terjadi perputaran ekonomi.

d. Variabel infrastuktur air bersih (INFAB) yang berdasarkan uji hipotesis pasial berpengaruh signifikan pada PDRB, sesuai dengan penelitian-penelitian terdahulu yang dilakukan oleh Rindang Bangun Prasetyo dan Muhammad Firdaus (2009), Ema Noviyanti Aminah (2017), Rusmusi IMP dan Dita Resmi Handayani (2018), Lise Pranessy dkk (2018), Azuwandri dkk (2019). Nilai koefisien regresi pada variabel INFAB yang sangat kecil yaitu 0,0000000238 yang artinya peningkatan 2,38E-08 atau 0,0000000238 rupiah PDRB karena penambahan 1 unit jaringan air bersih bila variabel lainnya tetap. Sejak tahun 2015 sampai 2017 (Tabel 1.7) dengan jumlah sambungan yang tidak bertambah dan penurunan yang cukup banyak pada tahun 2014 walaupun antara 2011 sampai 2013 jumlah sambungan terus meningkat. Perlu diingat bahwa data yang dalam penelitian ini hanya mencatat jumlah sambungan air bersih yang diusahakan oleh PDAM masing-masing kabupaten/kota, namun masih banyak jumlah sambungan di desa-desa baik yang dikelola oleh badan pengelola air minum atau Badan Usaha Milik Desa (BUMDesa) yang dimiliki oleh desa di mana pengusahaan air minum tersebut dinikmati oleh masyarakat desa yang jumlahnya tidak tercatat atau mungkin tidak terpublikasi. Demikian seharusnya data tentang jumlah sambungan air bersih harus dimasukkan data-data dari pengelolaan air bersih yang dilakukan oleh masyarakat dan peremntah-pemerintah desa, selain itu memperbanyak sambungan air yang dikelola masyarakat dan desa dapat menjadi solusi bila kemampuan PDAM untuk menambah jaringan terbatas mengingat air bersih besar manfaatnya untuk kehidupan dan perekonoimian karena juga termasuk bahan baku untuk usaha terutama kuliner.

e. Hasil uji parsial antara variabel infrastruktur hotel, penginapan dan restoran (INFHPR) terhadap PDRB menunjukkan hasil signifikan, hal ini sesuai dengan hasil penelitian Merlinawati Umar Amiri (2015), Yhoga Bagus Adhikrisna dkk (2016) dan Yenni Del Rosa dan Mohammad Abdilla (2018) serta Prasetyo Yekti Utomo dan Subyantoro (2018). Koefisien regresi variabel INFHPR artinya peningkatan 0,000421 rupiah PDRB karena penambahan 1 unit INFHPR (hotel, penginapan dan restoran) bila variabel lainnya tidak berubah. Angka yang cukup kecil itu diduga karena walaupun jumlah hotel, penginapan dan restoran naik tiap tahun seperti PDRB namun untuk jumlah restoran pada tahun 2016 terjadi penurunan drastis sebagaimana diuraikan pada Bab IV. Akan tetapi justru jumlah restoran lah yang berkesempatan untuk mudah ditambah demi menaikkan jumlah PDRB, caranya dengan mengoptimalisasi spot-spot wisata baru dan dipromosikan gar banyak pengunjungnya sehingga dapat menjadikan potensi untuk pendirian usaha restoran. 


\section{PENUTUP}

Hasil pelitian dapat disimpulkan bahwa; 1) Pengaruh variabel infrastruktur pendidikan (INFPEND) terhadap PDRB Jawa Tengah tahun 2011-2017 adalah signifikan positif; 2) Pengaruh variabel infrastruktur kesehatan (INFPKES) terhadap PDRB Jawa Tengah tahun 20112017 adalah signifikan positif; 3) Pengaruh variabel infrastruktur jalan (INFJ) terhadap PDRB Jawa Tengah tahun 2011-2017 adalah signifikan positif; 4) Pengaruh variabel infrastruktur air bersih (INFAB) terhadap PDRB Jawa Tengah tahun 2011-2017 adalah signifikan positiff; 5) Pengaruh variabel infrastruktur hotel, penginapan dan restoran (INFHPR) terhadap PDRB Jawa Tengah tahun 2011-2017 adalah signifikan positif.

Penelitian ini memberikan beberapa saran kebijakan yang dapat dilakukan meliputi; 1) Tawaran solusi agar pengaruh infrastruktur pendidikan terhadap PDRB semakin besar adalah dengan menjadikan produk dari pendidikan itu siap untuk berproduksi yaitu dengan memperbanyak sekolah kejuaruan/SMK kemudian menyalurkan ke pemberi kerja; 2) Solusi agar menaikkan PDRB dari sisi fasilitas kesehatan yaitu dengan memberikan fasilitas layanan kesehatan dengan kualitas lebih hingga ke desa-desa yaitu dengan memanfaatkan dana desa dari pusat yang dalam hal ini adalah dari sisi regulasi agar pemanfaatan dana desa untuk layanan kesehatan lebih ditingkatkan. Solusi kedua adalah bantuan Pemerintah Provinsi terutama yang bidang ketahanan masyarakat perlu digeser penggunaannya ke layanan kesehatan; 3) Saran untuk solusi dari sisi infrastruktur jalan adalah selain memperbaiki kualitas yang sekarang sudah dan sedang dilakukan yaitu dengan cara membangkitkan ekonomi masyarakat di sekitar jalan-jalan provinsi agar terjadi perputaran ekonomi;4) memperbanyak sambungan air yang dikelola masyarakat dan desa dapat menjadi solusi bila kemampuan PDAM untuk menambah jaringan terbatas mengingat air bersih besar manfaatnya untuk kehidupan dan perekonoimian karena juga termasuk bahan baku untuk usaha terutama kuliner; 5) Mengoptimalisasi spot-spot wisata baru dan dipromosikan agar banyak pengunjungnya sehingga dapat menjadikan potensi untuk pendirian usaha restoran karena justru jumlah restoran lah yang berkesempatan untuk mudah ditambah demi menaikkan jumlah PDRB.

\section{DAFTAR PUSTAKA}

Adhikrisna, Yhoga Bagus. dkk. (2016). Analisis Pengaruh Pariwisata Terhadap Produk Domestik Regional Bruto Kabupaten/Kota Provinsi Jawa Timur 2011-2014. Jurnal Ekonomi Pembangunan, Volume 14 Nomor 1, hlm. 59-70

Aminah, Ema Noviyanti. (2017). Pengaruh Infrastruktur Terhadap Pertumbuhan Ekonomi Di Jawa Tengah Tahun 2012-2014. Surakarta: Universitas Muhammadiyah Surakarta

Amiri, Merlinawati Umar dkk. (2015). Pengaruh Sektor Perdagangan, Hotel, Restoran Dan Sektor Jasa-Jasa Terhadap Produk Domestik Regional Bruto (PDRB) Kota Manado. Jurnal Berkala Ilmiah Efisiensi: Vol 15, No 4 (2015), hlm. 1-15

Antara, Made dan Sumarniasih, Made Sri. (2017). Role of Tourism in Economy of Bali and Indonesia. Journal of Tourism and Hospitality Management December 2017, Vol. 5, No. 2, hlm. 34-44 
Arikunto, Suharsimi. 2002. Prosedur Penelilian Suatu Pendekatan dan Praktik. Jakarta: Rineka Cipta

Astuti, Alfira Mulya. 2010. Fixed Effect Model pada Regresi Data Panel. Jurnal Beta: Vol. 3 No. 2, November 2010, hlm. 134-145

At-Thohiroh, Fatimah. (2018). Analisis Ketersediaan Infrastruktur Ekonomi dan Sosial terhadap Pertumbuhan Ekonomi di Kawasan Timur Indonesia (Periode 2010-2015). Jakarta: Fakultas Ekonomi Dan Bisnis Universitas Islam Negeri Syarif Hidayatullah

Awandari, Luh Putu Putri dan Indrajaya, I Gst Bgs. (2016). Pengaruh Infrastruktur, Investasi, dan Pertumbuhan Ekonomi Terhadap Kesejahteraan Masyarakat Melalui Kesempatan Kerja dengan Lokasi Penelitian di Provinsi Bali. E-Jurnal Ekonomi Pembangunan Universitas Udayana. Vol. 5 No. 12, Desember 2016, hlm. 1435-1462

Azuwandri dkk. (2019). Pengaruh Pembangunan Infrastruktur terhadap Pertumbuhan Ekonomi di Provinsi Bengkulu. Jurnal Ilmiah Ekonomi dan Bisnis: Vol 7 No 2 (2019), hlm. 199208

Badan Pusat Statistik Jawa Tengah. (2012). Jawa Tengah Dalam Angka 2012. Diunduh dari: jateng.bps.go.id tanggal 15 Maret 2018.

Badan Pusat Statistik Jawa Tengah. (2013). Jawa Tengah Dalam Angka 2013. Diunduh dari: jateng.bps.go.id tanggal 15 Maret 2018.

Badan Pusat Statistik Jawa Tengah. (2014). Jawa Tengah Dalam Angka 2014. Diunduh dari: jateng.bps.go.id tanggal 15 Maret 2018.

Badan Pusat Statistik Jawa Tengah. (2015). Jawa Tengah Dalam Angka 2015. Diunduh dari: jateng.bps.go.id tanggal 15 Maret 2018.

Badan Pusat Statistik Jawa Tengah. (2016). Jawa Tengah Dalam Angka 2016. Diunduh dari: jateng.bps.go.id tanggal 15 Maret 2018.

Badan Pusat Statistik Jawa Tengah. (2017). Jawa Tengah Dalam Angka 2017. Diunduh dari: jateng.bps.go.id tanggal 15 Maret 2018.

Basuki, Agus Tri dan Yuliadi, Imamudin. (2015). Electronic Data Processing (SPSS 15 dan Eviews 7), Edisi Revisi. Yogyakarta: Danisa Media

Budirahmayani, Anindita dan Khoirunurrofik. (2019). Tourism And Economic Growth: Spatial Perspective. Advances in Social Science, Education and Humanities Research (ASSEHR), volume 216 , hlm. 7-24

Canning. D., Fay M. dan Perotti R. (1994). Infrastructure and Growth, dalam International Differences in Growth Rates, edited by M. Baldassarri, M. Paganaetlo dan E.S. Phelps. New York: St. Martins Press. 
Čerović, Slobodan. et. al. (2015). The Contribution of Tourism Industry on the GDP growth of Western Balkan Countries. Industrija, Vol.43, No.3, 2015, hlm. 159-170

Del Rosa, Yenni dan Abdilla, Mohammad. (2018). Pengaruh Industri Pariwisata Terhadap PDRB Kota Padang. Jurnal Manajemen dan Kewirausahaan, Volume 9, Nomor 3, September 2018, hlm. 48-51

Dornbusch. R.. S.Fischer, and R.Slartz. (2008). Macroeconomics. 11th ed.. Boston: McGrawHill.

Easterly, William. dan Robelo, Sergio. (1993). Fiscal Policy and Economic Growth. Journal of Monetary Economics, 32.417-58

FaladeObalade, Timothy A. dan Dubey, Suchi. (2014). Managing Tourism as a source of Revenue and Foreign direct investment inflow in a developing Country: The Jordanian Experience. International Journal of Academic Research in Economics and Management Sciences, May 2014, Vol. 3, No. 3, hlm. 16-42

Ghosh, Budhadep. (2005). Investigating The Linkage Between Infrastructure and Regional Development in India: Era Of Planning To Globalization. Journal Of Asian Economics. Vol. 15, No. 6, hlm. 1024-1050

Gujarati, Damodar N dan Porter, Dawn C. (2013). Dasar-dasar Ekonometrika Edisi 5 Buku 2. Raden Carlos Mangunsong (Terjemahan). Jakarta: Salemba Empat.

Hogendorn, J.S. 1992. Economic Development. New York: Harper Collins.

IMP, Rusmusi dan Handayani, Dita Resmi. (2018). Pengaruh Investasi Infrastruktur Jalan, Air dan Pendidikan Terhadap Pertumbuhan Ekonomi Jawa Tengah Tahun 2011-2015. Jurnal Ekonomi, Bisnis dan Akuntansi (JEBA)Volume 20 Nomor 03 Tahun 2018, hlm. 1-13

Jayme, Frederico, G. et al. (2009). Public Expenditure On Infrastructure And Economic Growth Acros Brazilian States. Journal Of Economic Literature Number 346

Wibowo, Agung Budi Luhur. (2016). Pengaruh Infrastruktur Ekonomi Dan Sosial Terhadap Pertumbuhan Ekonomi di Indonesia Tahun 2006-2013. Yogyakarta: Fakultas Ekonomi Universitas Negeri Yogyakarta

Mankiw, Gregory. (2012). Macroeconomics, Eighth Edition. New York: Worth Publishers.

Mc Taggart, Douglas et. al. (2012). Macroeconomics. Seventh Edition. Frenchs Forest NSW: Addison Wesley.

Moh., Nazir. (1999). Metode Penelitian, Cetakan Ketiga. Jakarta: Ghalia Indonesia.

Peraturan Daerah Jawa Tengah Nomor 2 Tahun 2007 tentang Rencana Pembangunan Jangka Panjang Daerah Jawa Tengah Tahun 2005-2025. 
Peraturan Daerah Jawa Tengah Nomor 2 Tahun 2017 tentang Rencana Pembangunan Jangka Menengah Daerah Jawa Tengah Tahun 2017-2022.

Pranessy, Lise dkk. (2018). Pengaruh Pembangunan Infrastruktur terhadap Pertumbuhan Ekonomi Provinsi Bengkulu. Jurnal Ekonomi dan Perencanaan Pembangunan: Volume 4 Nomor 3, hlm. 51-62

Prasetyo, Rindang Bangun dan Firdaus, Muhammad. (2009). Pengaruh Infrastruktur Pada Pertumbuhan Ekonomi Wilayah di Indonesia. Jurnal Ekonomi dan Kebijakan Pembangunan Vol. 2 No. 2, hlm. 222-236

Priyono. (2016). Metode Penelitian Kuantitatif. Sidoarjo: Zifatama.

Ritonga, Mariyatul Kubtiyah. (2014). Pengaruh Pembangunan Infrastruktur Kesehatan, Pendidikan dan Jumlah Penduduk Terhadap Pertumbuhan Ekonomi di KabupatenKabupaten Provinsi Sumatera Utara. Medan: Universitas Negeri Medan, Master Thesis

Startz, Richard. (2019). Eviews Illustrated. Santa Barbara: IHS Global Inc.

Sugiyono. (2007). Statistika Untuk Penelitian. Bandung: CV. Alfabeta.

Suminar, Hasti Aringga dkk. (2016). Pengaruh Pembangunan Infrastruktur terhadap Pendapatan Regional Kabupaten Jember. Jurusan Ilmu Ekonomi dan Studi Pembangunan, Fakultas Ekonomi, Universitas Jember (UNEJ): Jurnal Mahasiswa, hlm. 1-5

Sunarto dan Setiono, Bambang. (2007). Ekonomi Makro: Edisi Ketiga. Jakarta: Pusat Pendidikan dan Pelatihan Pengawasan Badan Pengawasan Keuangan Pembangunan

Taylor-Lewis. R. (1995). The Role of Infrastructure in Productivity and Output Growth: A Case Study of the Group of Seven'. Unpublished Ph.D. Dissertation. College Park. MD: University of Maryland. 1993.

Todaro, Michael P dan Smith, Stephen C. (2012). Economics Development Eleventh Edition. Boston: Pearson Education, Inc.

Todaro, Michael P. (2000). Pembangunan Ekonomi di Dunia Ketiga (H.Munandar, Trans. Edisi Ketujuh ed.). Jakarta: Erlangga.

Utomo, Prasetyo Yekti dan Subyantoro. (2018). Peranan Sektor Perdagangan, Hotel dan Restoran dalam Peningkatan Pertumbuhan Ekonomi Kota Madiun Tahun 2006-2015. Jurnal Epicheirisi: Volume 2 Nomor 1 Tahun 2018, hlm. 26-31

World Bank (1994). World Development Report 1994 - Infrastructure for Development. New York: Oxford University Press. 